\title{
The Intervention of CRAC Channels Alleviates Inflammatory Responses in Nasal Polyps
}

\author{
Lin Lin Fei Dai Zhongchun Chen Lihui Cai \\ Department of Otorhinolaryngology-Head and Neck Surgery, Huashan Hospital of Fudan University, Shanghai, \\ PR China
}

\section{Key Words \\ Nasal polyps $\cdot$ Orai $1 \cdot \mathrm{Ca}^{2+}$ release-activated $\mathrm{Ca}^{2+}$. \\ 2-Aminoethoxydiphenyl borate $\cdot$ Mean fluorescence intensity $\cdot$ Inflammatory mediators}

\begin{abstract}
Background: Chronic rhinosinusitis with nasal polyps (CRSwNP) is associated with Th2-dominant inflammation. However, effective treatments for CRSwNP have not yet been found. This study aimed to investigate the expression of Orai1 in nasal polyps (NP) and the influence on them of the intervention of $\mathrm{Ca}^{2+}$ release-activated $\mathrm{Ca}^{2+}(\mathrm{CRAC})$ channels. Materials and Methods: Nasal samples were obtained from normal subjects or subjects with CRSwNP. We studied the distribution of Orai1 protein in NP and normal mucosa (normal group) using immunohistochemistry. These tissues in cultures were then maintained in the absence (control group) or presence of 2-aminoethoxydiphenyl borate (2APB) for $24 \mathrm{~h}$. Orai1 was examined by means of enzymelinked immunosorbent assay (ELISA) and real-time reverse transcription-polymerase chain reaction (RT-PCR). The $\mathrm{Ca}^{2+}$ mean fluorescence intensity (MFI) was evaluated by flow cytometry, and the inflammatory mediators, including interleukin (IL)-4, IL-5, IL-13, Dermatophagoides pteronyssinusspecific lgE, leukotriene $\mathrm{C} 4$ and eosinophil cation protein in cultures, were analyzed with ELISA and real-time RT-PCR. $R \boldsymbol{e}$ -
\end{abstract}

sults: The expression of Orai1 was localized to the cytoplasmic membrane of inflammatory cells, and upregulated in NP compared to that in the normal group. However, Orai1 protein was decreased in polyp tissues after the 2-APB treatment. The levels of $\mathrm{Ca}^{2+} \mathrm{MFI}$ and above inflammatory mediators were also elevated in NP, and reduced after the 2-APB administration compared to those in the control group. Conclusions: Orai 1 and CRAC channels may play a crucial role in NP formation and development, and the 2-APB intervention of Orai1 protein may alleviate inflammatory responses in NP.

(c) 2015 S. Karger AG, Basel

\section{Introduction}

The pathogenesis of nasal polyps (NP) still remains unclear, although there have been advances in genetics, molecular biology and immunology. NP tissues arise from the mucosa of the nasal cavity or nasal sinuses, and are characterized by morphological changes, such as the hyperplasia and metaplasia of epithelial cells, the infiltration of inflammatory cells, including lymphocytes, mast cells and eosinophils [1], and the stromal edema and fibrosis.

\section{L.L. and F.D. contributed equally to this work.}

\section{KARGER 125}

(c) 2015 S. Karger AG, Base

$1018-2438 / 15 / 1674-0270 \$ 39.50 / 0$

E-Mail karger@karger.com

www.karger.com/iaa
Correspondence to: Dr. Lin Lin

Department of Otorhinolaryngology-Head and Neck Surgery Huashan Hospital of Fudan University

12 Wulumuqi Middle Road, Shanghai 200040 (PR China)

E-Mail linlinhsn@aliyun.com 
Patients with chronic rhinosinusitis with NP (CRSwNP) always present with nasal obstruction, rhinorrhea, anosmia and postnasal drip. Systemic and topical steroids have been used effectively in the treatment of NP [2]. However, these drugs have some side effects consisting of epistaxis, itching, sneeze, dry nose and rhinitis [3]. Therefore, a novel therapeutic strategy for CRSwNP is urgently needed.

It is well known that intracellular $\mathrm{Ca}^{2+}$ signals regulate a diverse array of physiologic processes, including cellular secretion, cell growth and gene expression [4]. Changes of cytoplasmic $\mathrm{Ca}^{2+}$ levels are caused by an altered flux across the plasma membrane, and by release from endoplasmic reticulum. Store-operated $\mathrm{Ca}^{2+}$ entry (SOCE) is activated by the depletion of $\mathrm{Ca}^{2+}$ stores in endoplasmic reticulum [5]. $\mathrm{Ca}^{2+}$ release-activated $\mathrm{Ca}^{2+}$ (CRAC) channels are the characterized SOCE pathway, and Orail has been identified as a key component of CRAC channels [6]. Sustained $\mathrm{Ca}^{2+}$ influx results in the sharp elevation of intracellular $\mathrm{Ca}^{2+} . \mathrm{Ca}^{2+}$ signaling activates cytoplasmic transcription factors of the dephosphorylation of the nuclear factor of activated T cells (NFAT) family, and then facilitates the NFAT translocation to the nucleus of immune system cells (ISC) [7]. The activation of NFAT induces and accelerates Th2 cell responses such as the local release of interleukin (IL)-4, IL- 5 and IL- 13 by Th2 cells [8]. Orail protein is crucial for SOCE and CRAC channel activities. Its defect directly contributes to the dysfunction of CRAC channels [5]. In addition, CRSwNP is primarily characterized by eosinophilic inflammation and prevalent Th2 responses [9]. Therefore, we hypothesize that the Orail/CRAC/NFAT pathway may play a role in the pathogenesis of NP.

The aim of this study was to analyze Orail expression in NP, and to evaluate whether the intervention of the Orail pathway was able to control the inflammation involved in NP. It has been reported that 2-aminoethoxydiphenyl borate (2-APB) is regarded as a useful pharmacologic tool in the study of SOCE. This drug influences SOCE by regulating CRAC channel activities [10]. In the current experiment, we studied the expressions of Orail protein and $\mathrm{Ca}^{2+}$ mean fluorescence intensity (MFI) in NP tissues. We then administered 2-APB into the cultured NP to investigate the change of this protein production and the level of $\mathrm{Ca}^{2+} \mathrm{MFI}$ after this treatment. Finally, we examined the concentrations of inflammatory mediators, including IL-4, IL-5, IL13, Dermatophagoides pteronyssinus (DP)-specific IgE (sIgE), leukotriene (LT)C4 and eosinophil cation protein (ECP) in the cultures after the 2-APB application.
Table 1. Patient characteristics

\begin{tabular}{lll}
\hline & Normal & NP \\
\hline Subjects, n & 12 & 18 \\
Median age (range), years & $46(24-55)$ & $50.5(27-68)$ \\
Female/male, n & $5 / 7$ & $7 / 11$ \\
History of asthma, n & 0 & 0 \\
SPT positive (DP), $\mathrm{n}$ & 0 & 18 \\
Topical steroids, n & 0 & 0 \\
Oral steroids, n & 0 & 0 \\
Antihistamines, n & 0 & 0 \\
Antibiotics, n & 0 & 0 \\
\hline
\end{tabular}

To the best of our knowledge, we are the first to evaluate the role of Orail protein and CRAC channels in the etiology of NP.

\section{Materials and Methods}

NP were obtained by functional endoscopic sinus surgery from patients that suffered from CRSwNP, who were referred to the Department of Otorhinolaryngology-Head and Neck Surgery, Huashan Hospital of Fudan University, Shanghai, China. The diagnosis of CRSwNP was in accordance with European Position Paper on Rhinosinusitis and Nasal Polyps 2012 [3]. Patients with an established classic allergic fungal sinusitis, aspirin intolerance, cystic fibrosis, immunodeficiency, coagulation disorder, ChurgStrauss syndrome or pregnancy were excluded from the study. All the patients had not received any medication (topical or oral steroids, antihistamines or antibiotics) for at least 1 month before surgery. The atopic status of these patients was evaluated according to skin reactivity to DP on skin prick test (SPT). The reaction to the SPT was considered positive if the wheal area caused by the allergen was greater than $7 \mathrm{~mm}^{2}$ (diameter $>3 \mathrm{~mm}$ ). The normal group (normal mucosa) consisted of samples collected from the inferior turbinates of patients undergoing nasal septoplasty-inferior turbinoplasty because of nasal obstruction. Details of the patient characteristics are provided in table 1 . This study was approved by the Ethical Committee of Huashan Hospital of Fudan University, and signed informed consent was obtained from all patients.

\section{Sample Preparation}

Samples from inferior turbinates and NP were obtained and cut into four portions: one was frozen at $-70^{\circ} \mathrm{C}$ for extraction, one was immersed in $10 \%$ neutral-buffered formalin for immunohistochemical analysis, one was analyzed by flow cytometry and one was cultured for treatments.

\section{Organ Culture of Normal Mucosa and NP}

Normal mucosa and NP were cultured using the air-liquid interface method [11]. The above tissues were cut using blades into 2 - to $3-\mathrm{mm}^{3}$ pieces under sterile conditions. Tissue fragments were washed three times with phosphate-buffered saline (PBS) contain- 
ing an antimycotic ( $5 \mu \mathrm{g} / \mathrm{ml}$ Fungizone) and an antibiotic (300 $\mu \mathrm{g} /$ $\mathrm{ml}$ penicillin $\mathrm{G}$ ), and then rinsed with $98 \%$ Dulbecco's minimum essential medium (DMEM) supplemented with $10 \%$ calf serum and gentamicin $(20 \mu \mathrm{g} / \mathrm{ml})$. To determine the effects of 2 -APB treatment on NP, the above tissues were then saturated for $1 \mathrm{~h}$ in culture medium (DMEM $+10 \%$ calf serum $+10 \mu \mathrm{g} / \mathrm{ml}$ gentamicin $)$ in the absence (the NP or control group) or presence of 2 -APB (30 or $50 \mu \mathrm{M}$; the 2-APB treatment group) [12], and then placed on a hydrated $1 \times 1-\mathrm{cm}$ gelatin sponge with the mucosa facing upward and the submucosa downward. Each sponge was placed in a well of a 6 -well plate containing $3 \mathrm{ml}$ of culture medium so that the mucosa was above the liquid phase. These plates were then placed in a humidified incubator and maintained at $37^{\circ} \mathrm{C}$ in a $95 \%$ air $/ 5 \%$ $\mathrm{CO}_{2}$ atmosphere under continuous shaking at $15 \mathrm{rpm}$ for $24 \mathrm{~h}$. After that, the tissues and the conditioned media were collected and stored at $-20^{\circ} \mathrm{C}$ until further use.

\section{Immunohistochemistry}

A portion of the samples received immunohistochemical staining. Sections were deparaffinized and rehydrated with water. Endogenous peroxidase was blocked using $3 \%$ hydrogen peroxide for $10 \mathrm{~min}$. Normal goat serum (Vector Lab, Burlingame, Calif., USA) was used to block nonspecific binding sites, and the primary Orail antibody (New East Biosciences, Malvern, Pa., USA) in antibody diluent (Dako, Carpinteria, Calif., USA) at 1:100 dilution was immediately applied to the sections and incubated for $45 \mathrm{~min}$. Unbound antibody was removed by three washes in PBS solution. Biotinylated anti-rabbit polyclonal IgG (Vector Lab) was applied to each section for $30 \mathrm{~min}$, followed by $20 \mathrm{~min}$ incubation with horseradish peroxidase streptavidin (Vector Lab). Slides were washed in PBS, stained with 3,3'-diaminobenzidine chromogen (DAB; Sigma-Aldrich, St. Louis, Mo., USA) for 5 min and counterstained with hematoxylin. Antibody localization was detected microscopically by brown staining. For Orail staining, the intensities were scored as no staining $(0)$, weak staining $(1+)$, moderate staining $(2+)$ or strong staining $(3+)$. The percentage of the staining area was classified as $0,0 \% ; 1,1-10 \% ; 2,11-50 \% ; 3,51-100 \%$. The intensity and percentage scores were multiplied to give a composite score of 1-9 for each specimen. Composite scores of 1-3 were defined as low Orail expression, and scores of 4-9 were considered to be high expression of Orail. The microscopic examination and scoring of staining degrees were performed at a magnification of $\times 400$ by two independent observers who were blinded to the subject groups.

\section{Flow Cytometry}

Cell suspensions prepared from normal mucosa and NP were centrifuged for $10 \mathrm{~min}$ at $200 \mathrm{~g}$ at $4^{\circ} \mathrm{C}$, and the cells were then harvested for flow cytometry analysis. The cells were resuspended in complete RPMI medium at $5 \times 10^{6} / \mathrm{ml}$ concentration, and were loaded with $5 \mu \mathrm{M}$ fluo- 3 in the presence of $100 \mu \mathrm{g} / \mathrm{ml}$ pluronic F-127 (Molecular Probes) at $37^{\circ} \mathrm{C}$ for $60 \mathrm{~min}$ under shaking. The cells were diluted in complete RPMI medium to $5 \times 10^{5} / \mathrm{ml}$ concentration, and incubated for $1 \mathrm{~h}$ at $37^{\circ} \mathrm{C}$. After two washings with glucose containing PBS, the cells were resuspended in complete RPMI medium at a concentration of $5 \times 10^{5}$ cells $/ \mu$. Fluorescence intensities were measured in the resuspended cells by FACScalibur (Becton Dickinson, Mountain View, Calif., USA). The mean fluorescence intensities were calculated by the Becton Dickinson CellQuest software.

\section{Enzyme-Linked Immunosorbent Assay}

Another portion of frozen tissues was sliced into small pieces and homogenized, and then lysed in RIPA buffer (Sigma-Aldrich) containing a protease inhibitor cocktail (Sigma-Aldrich). Tissue Orail protein from inferior turbinates and NP was measured using a 96-well microplate (Corning Inc., New York, N.Y., USA) coated with $1 \mu \mathrm{g} / \mathrm{ml}$ Orail antibody (New-East Biosciences, Malvern, $\mathrm{Pa}$., USA), and incubated overnight at $4{ }^{\circ} \mathrm{C}$. After washing, the microplate was incubated in $3 \%$ bovine serum albumin (Calbiochem, $\mathrm{La}$ Jolla, Calif., USA) at $37^{\circ} \mathrm{C}$ for $1 \mathrm{~h}$. Samples at 1:10 dilution were then added, followed by incubation at $37^{\circ} \mathrm{C}$ for $1 \mathrm{~h}$. After washing, Orail antibody that had been biotinylated using a biotinylation kit (American Qualex International Inc., San Clemente, Calif., USA) was then added at $1 \mu \mathrm{g} / \mathrm{ml}$, and allowed to incubate at $25^{\circ} \mathrm{C}$ for $1 \mathrm{~h}$. After washing, $1.5 \mu \mathrm{g} / \mathrm{ml}$ of streptavidin peroxidase was added followed by incubation at $25^{\circ} \mathrm{C}$ for $1 \mathrm{~h}$. After washing, tetramethylbenzidine (TMB) substrate [ $12.5 \mathrm{ml}$ citric phosphate buffer, 200 $\mu \mathrm{l}$ of TMB stock solution (6 mg/ml in DMSO), $100 \mu \mathrm{l} 1 \% \mathrm{H}_{2} \mathrm{O}_{2}$; Fluka Chemical Co., Ronkonkoma, N.Y., USA] was added to produce a color reaction. The reaction was terminated by the addition of $6 \mathrm{~N} \mathrm{H}_{2} \mathrm{SO}_{4}$. The optical density was determined at $450 \mathrm{~nm}$ using a microplate reader (MTP-32; Corona Electric, Ibaraki, Japan).

For the measurement of DP-sIgE, the procedure was essentially the same as the above method except that the microplates were coated with DP $(2 \mu \mathrm{g} /$ well; Allergopharma, Reinbek, Germany) instead of the Orail antibody, and a fixed sample dilution was used (1:50 dilution in blocking buffer). Concentrations of IL-4, IL-5, IL13, LTC4 and ECP were evaluated using the corresponding enzyme-linked immunosorbent assay (ELISA) kits purchased from Abcam (Cambridge, UK; for IL-4 and IL-13), Ever Systems Biology Laboratory Inc. (Sacramento, Calif., USA; for IL-5 and LTC4) and Panpacific Tech Co. (Missouri City, Tex., USA; for ECP). The ELISAs were performed according to the manufacturers' protocols.

Real-Time Reverse Transcription-Polymerase Chain Reaction

Primers were designed using Primer Express software (Applied Biosystems, Foster City, Calif., USA) from the sequence available in Genbank, and were synthesized (Geneland Biotech, Shanghai, China). Real-time reverse transcription-polymerase chain reaction (RT-PCR) was performed to detect the mRNAs of Orail, IL-4, IL-5, IL-13, DP-sIgE (germline C $\varepsilon$ transcripts), LTC4 synthase (LTC4S) and ECP (eosinophil-associated, ribonuclease A family, member 3; EAR3). The primers used were as follows: Orai1, forward primer $5^{\prime}$-CCCTTCGGCCTGATCTTTATC- $3^{\prime}$ and reverse primer 5'-GGAACTGTCGGTCAGTCTTATG-3'; IL-4, forward primer $5^{\prime}$-ATTTCTCTCTCATGATCGTC- $3^{\prime}$ and reverse primer 5'-GGACACAAGTGCGATATCACC-3'; IL-5, forward primer $5^{\prime}$-GGATGCTTCTGCATTTGAGTTT- ${ }^{\prime}$ and reverse primer $5^{\prime}$ CAGTGCCAAGGTCTCTTTCA-3'; IL-13, forward primer $5^{\prime}$ GAGTGTGTTTGTCACCGTTG-3' and reverse primer $5^{\prime}$-TACTCGTTGGTCGAGAGCTG-3'; Germline C $\varepsilon$ transcripts, forward primer $5^{\prime}$-CACGCTCTCTGGTCACTATG-3' and reverse primer 5'-CAGGACGACTGTAAGATCTTCACG-3'; LTC4S, forward primer $5^{\prime}$-CTCCATTCTGAAGCCAAA- $3^{\prime}$ and reverse primer $5^{\prime}$-AGACCGCCTCACCACTT-3'; EAR3, forward primer $5^{\prime}$-GTAGATTCCGGGTGCCTTTAC- $3^{\prime}$ and reverse primer $5^{\prime}$ GCAACTACATAGAACCTCCTTCC- $3^{\prime}$. $\beta$-Actin mRNA was also examined to control the sample-to-sample variation in RNA isolation and integrity by using a pair of primers: forward primer 


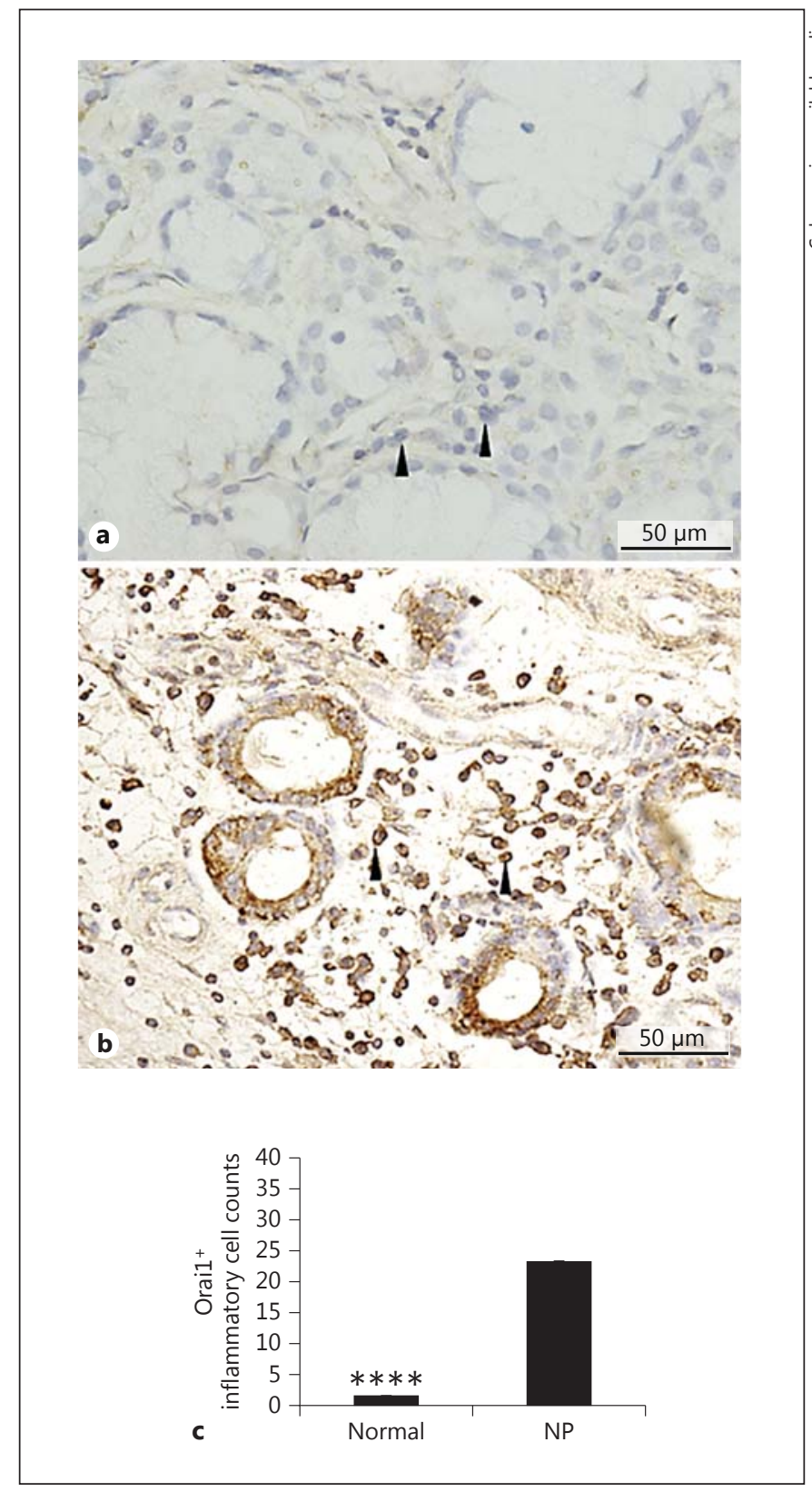

Fig. 1. Immunohistochemical analysis of Orai1 expression in normal mucosa (a) and NP (b). The arrowheads show the staining of inflammatory cells. Original magnification $\times 400$. c Increased number of Orai1 $1^{+}$inflammatory cells in the NP compared to normal group. ${ }^{* * * *} \mathrm{p}<0.0001$ vs. NP.

$5^{\prime}$-CACTCTTCCAGCCTTCCTTC- $3^{\prime}$ and reverse primer $5^{\prime}$ GTACAGGTCTTTGCGGATGT- $3^{\prime}$. The specificity of PCR products was evaluated by melting curve analysis and by size in agarose gels. We controlled for linearity of PCR amplification using 3 dilutions of complementary DNA. The evaluation of data was performed using threshold cycle values with $\beta$-actin as the internal standard.

2-APB Alleviates Inflammation in NP
Table 2. Orail expression in NP

\begin{tabular}{lll}
\hline Staining area & $\begin{array}{l}\text { Normal } \\
\text { inflammatory cells }\end{array}$ & $\begin{array}{l}\text { NP } \\
\text { inflammatory cells }\end{array}$ \\
\hline Patients, $\mathrm{n}$ & 12 & 18 \\
Score 1-3, n & 12 & 0 \\
Score 4-9, n & 0 & 18 \\
\hline
\end{tabular}

\section{Statistical Analysis}

Statistical analysis was performed with a commercially available statistical software prism 6.0 (GraphPad Software Inc., San Diego, Calif., USA). The Kruskal-Wallis test was performed for comparisons between patient groups. A nonparametric MannWhitney test was applied if the initial Kruskal-Wallis test was significant. $p<0.05$ was considered to be statistically significant.

\section{Results}

\section{Immunohistochemical Analysis of Orai1 in NP}

To evaluate the expression of Orail protein in NP, we performed immunohistochemical staining. As shown in figure 1, we detected Orail staining in submucosal inflammatory cells (fig. 1a, b), and this protein was localized to the plasma membrane of inflammatory cells. However, Orail was negatively stained in epithelial cells of NP (unpubl. data). We did not discriminate the types of Orai $1^{+}$inflammatory cells further because they all played important roles in the development of NP [1]. Positive staining cells appeared brown, and intense staining was found in polyp tissue. A higher expression of Orai1 was observed in the infiltrated inflammatory cells (score 4-9) of NP when compared to that of normal mucosa (score 1-3; table 2). Furthermore, we counted the number of Orai $1^{+}$inflammatory cells using a semiquantitative method, and confirmed that their numbers were increased in NP compared to those seen in normal mucosa from inferior turbinate ( $p<0.0001$; fig. 1c). The results showed that Orail and CRAC channels existed in inflammatory cells, and were upregulated in the condition of NP.

\section{Upregulation of Orail Protein and $\mathrm{Ca}^{2+}$ MFI in NP}

To determine the expression of Orail protein in NP, the extracted protein from inferior turbinates and NP were examined by ELISA. The result demonstrated that Orail was increased in NP tissues from patients with CRSwNP in comparison with normal samples ( $p<0.0001$, normal vs. NP; fig. 2a). In addition, real-time RT-PCR 


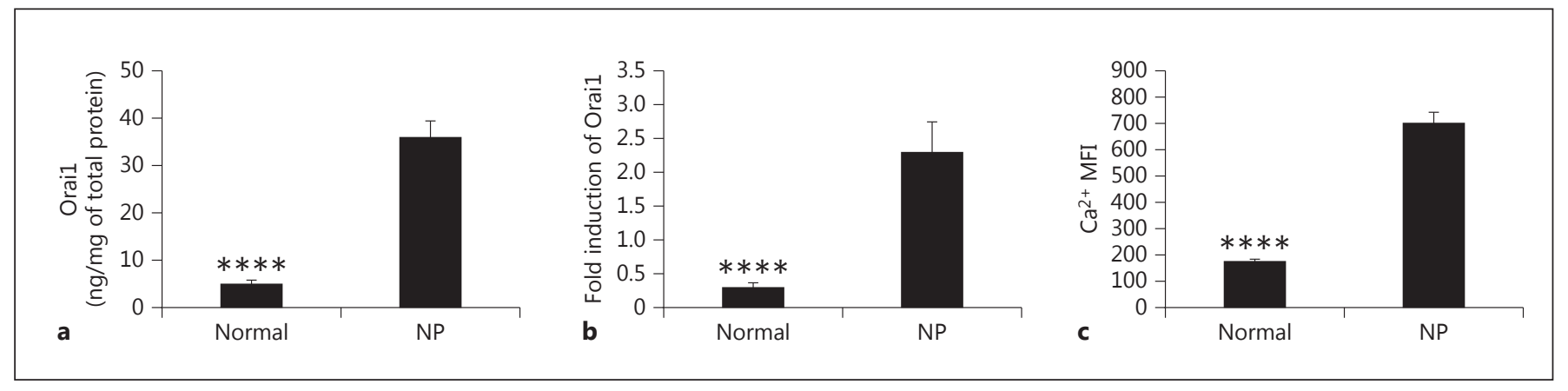

Fig. 2. The expressions of Orail and $\mathrm{Ca}^{2+} \mathrm{MFI}$ in normal mucosa and NP. a ELISA analysis of Orail. b Real-time RT-PCR analysis of Orai1. c Flow cytometry analysis of $\mathrm{Ca}^{2+}$ MFI. ${ }^{* * * *} \mathrm{p}<0.0001$ vs. NP.

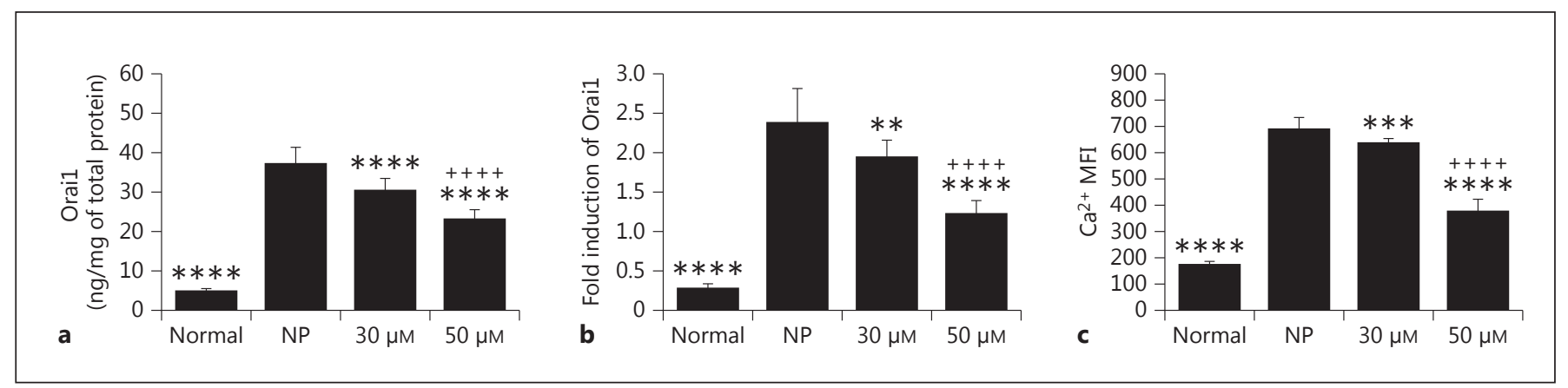

Fig. 3. The expressions of Orail and $\mathrm{Ca}^{2+} \mathrm{MFI}$ in normal mucosa and NP after 2-APB treatment. a ELISA analysis of Orai1. b Real-time RT-PCR analysis of Orai1. c Flow cytometry analysis of $\mathrm{Ca}^{2+}$ MFI. ${ }^{* *} \mathrm{p}<0.01,{ }^{* * *} \mathrm{p}<$ $0.001,{ }^{* * * *} \mathrm{p}<0.0001$ vs. NP; ${ }^{+++} \mathrm{p}<0.0001$ vs. $30 \mu \mathrm{M}$.

was performed to assess Orail mRNA in the above tissues. The production of Orail mRNA was enhanced in $\mathrm{NP}$ compared to that seen in normal mucosa ( $\mathrm{p}<0.0001$, normal vs. NP; fig. $2 \mathrm{~b}$ ). To assess the influence of Orai1 protein and CRAC channels on the intracellular concentration of $\mathrm{Ca}^{2+}$, flow cytometry was performed to examine the level of $\mathrm{Ca}^{2+}$ MFI in these tissues. We found that $\mathrm{Ca}^{2+}$ MFI was upregulated in NP in comparison with that in normal mucosa ( $<<0.0001$, normal vs. NP; fig. $2 c)$. The results implied that excessive Orail expression activated CRAC channels in polypoid tissues.

\section{Orail and $\mathrm{Ca}^{2+}$ MFI Expression in the Cultured NP after 2-APB Administration}

The extracted Orail protein and mRNA from the cultured NP were evaluated by ELISA and real-time RTPCR to assess the influence of 2-APB on their expressions. As shown in figure $3 \mathrm{a}$ and $\mathrm{b}$, Orail protein and mRNA were upregulated in NP compared to in normal mucosa $(\mathrm{p}<0.0001$ and $\mathrm{p}<0.0001$, respectively, normal vs. NP; fig. 3a, b). However, 2-APB administration reduced their expressions $(\mathrm{p}<0.0001$ and $\mathrm{p}<0.01$, respectively, $30 \mu \mathrm{M}$ vs. NP; $\mathrm{p}<0.0001$ and $\mathrm{p}<0.0001$, respectively, $50 \mu \mathrm{M}$ vs. NP; fig. $3 \mathrm{a}, \mathrm{b}$ ). As for $\mathrm{Ca}^{2+} \mathrm{MFI}$, the content was increased in NP compared to that in normal mucosa ( $\mathrm{p}<0.0001$, normal vs. NP; fig. $3 \mathrm{c}$ ). However, 2 -APB application decreased the level $(\mathrm{p}<0.001,30 \mu \mathrm{M}$ vs. NP; $p<0.0001,50 \mu \mathrm{M}$ vs. NP; fig. $3 \mathrm{c}$ ). The results indicated that Orail and $\mathrm{Ca}^{2+}$ MFI were upregulated in the cultured NP, and downregulated after in vitro $2-\mathrm{APB}$ treatment.

\section{ELISA Analysis of IL-4, IL-5, IL-13, DP-sIgE, LTC4 and ECP in Culture after 2-APB Treatment}

ELISA was performed to analyze the concentrations of IL-4, IL-5, IL-13, DP-sIgE, LTC4 and ECP in the culture medium. The above substances were all upregulated in the NP cultures compared to those in the normal mucosal cultures, and all downregulated after 2-APB treatment (respectively, $\mathrm{p}<0.0001$, normal vs. NP, $\mathrm{p}<0.0001$, 

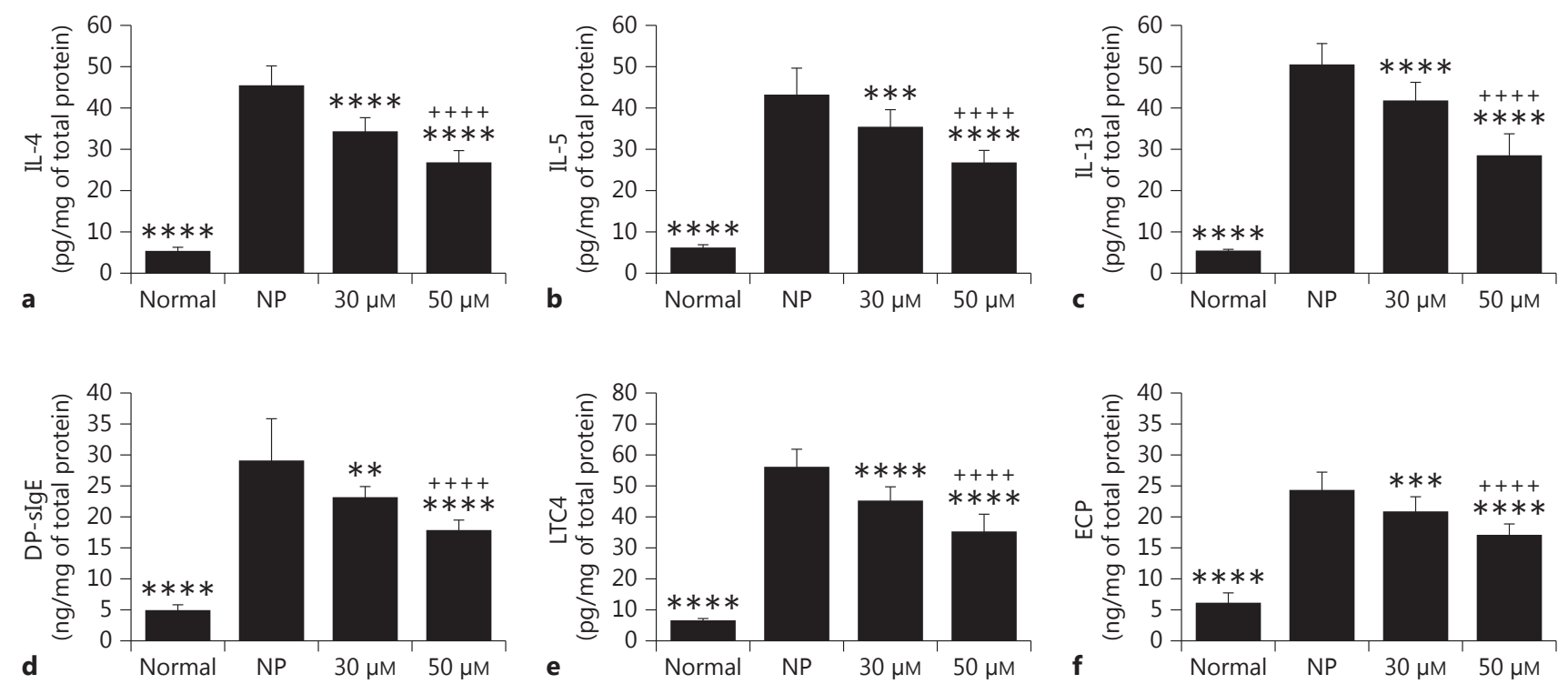

Fig. 4. ELISA analysis of IL-4 (a), IL-5 (b), IL-13 (c), DP-sIgE (d), LTC4 (e) and ECP (f) in the cultures of normal mucosa and NP after 2 -APB treatment. ${ }^{* *} \mathrm{p}<0.01,{ }^{* * *} \mathrm{p}<0.001,{ }^{* * * *} \mathrm{p}<0.0001 \mathrm{vs.} \mathrm{NP}{ }^{++++} \mathrm{p}<0.0001 \mathrm{vs}$. $30 \mu \mathrm{M}$.

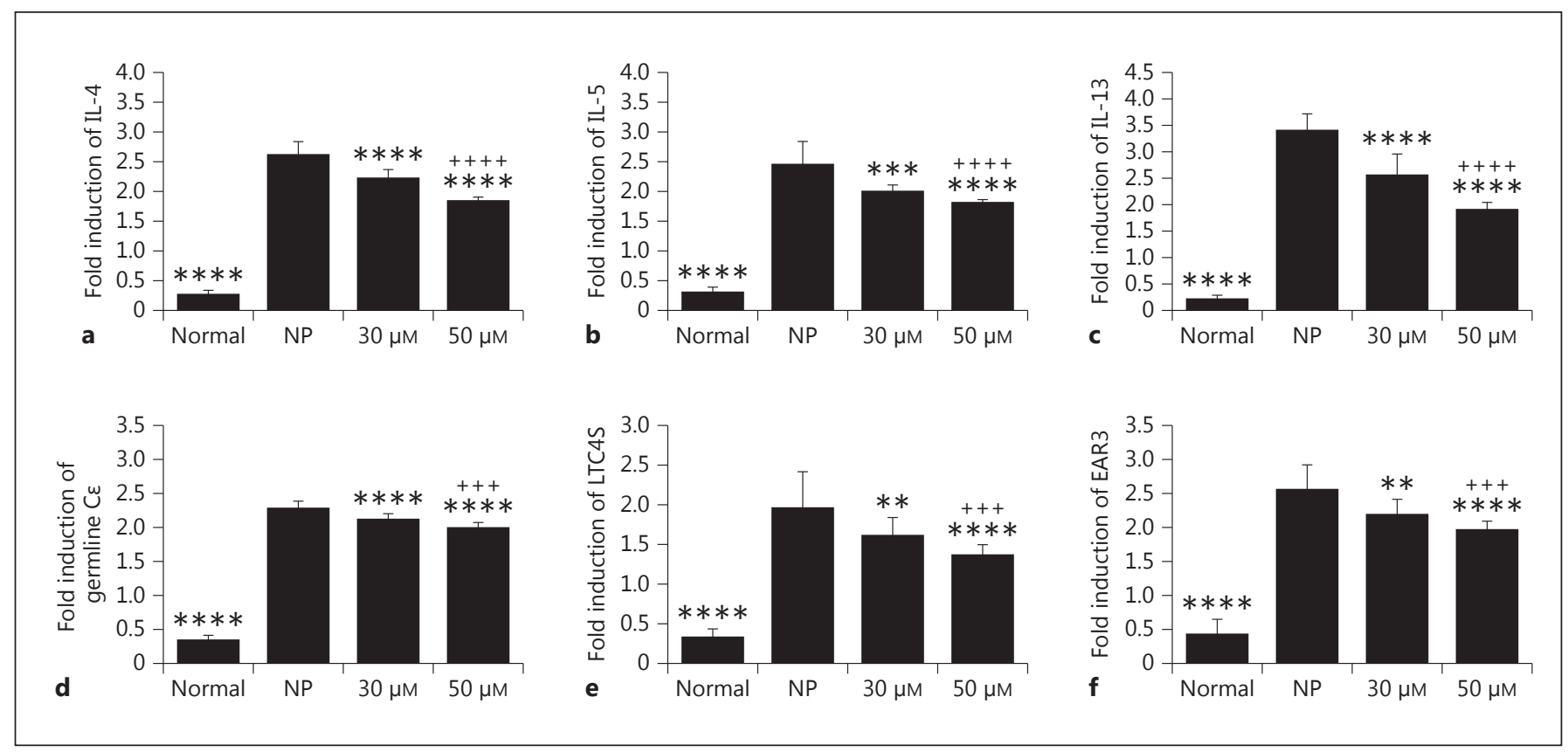

Fig. 5. Real-time RT-PCR analysis of mRNAs of IL-4 (a), IL-5 (b), IL-13 (c), germline Ce transcripts (d), LTC4S (e) and EAR3 (f) in the cultures of normal mucosa and NP after 2-APB treatment. ${ }^{* *} \mathrm{p}<0.01,{ }^{* * *} \mathrm{p}<0.001$, **** $\mathrm{p}<0.0001$ vs. NP; ${ }^{+++} \mathrm{p}<0.001,{ }^{++++} \mathrm{p}<0.0001$ vs. $30 \mu \mathrm{M}$. 
$30 \mu \mathrm{M}$ vs. NP, $\mathrm{p}<0.0001,50 \mu \mathrm{M}$ vs. NP; $\mathrm{p}<0.0001$, normal vs. NP, $\mathrm{p}<0.001,30 \mu \mathrm{M}$ vs. NP, $\mathrm{p}<0.0001,50 \mu \mathrm{M}$ vs. NP; $\mathrm{p}<0.0001$, normal vs. NP, $\mathrm{p}<0.0001,30 \mu \mathrm{M}$ vs. NP, $\mathrm{p}<$ $0.0001,50 \mu$ v vs. NP; $p<0.0001$, normal vs. NP, $p<0.01$, $30 \mu \mathrm{M}$ vs. NP, $\mathrm{p}<0.0001,50 \mu \mathrm{M}$ vs. NP; $<<0.0001$, normal vs. NP, $\mathrm{p}<0.0001,30 \mu \mathrm{M}$ vs. NP, $\mathrm{p}<0.0001,50 \mu \mathrm{M}$ vs. NP; $\mathrm{p}<0.0001$, normal vs. NP, $\mathrm{p}<0.001,30 \mu \mathrm{M}$ vs. NP, $\mathrm{p}<$ $0.0001,50 \mu \mathrm{M}$ vs. NP; fig. 4). The results illustrated that 2 -APB treatment might prohibit the development of NP.

Real-Time RT-PCR Analysis of $m R N A$ s of IL-4, IL-5, IL-13, Germline Ce Transcripts, LTC4S and EAR3 in the Culture after 2-APB Treatment

Real-time RT-PCR was performed to evaluate the contents of mRNAs of IL-4, IL-5, IL-13, germline C $\varepsilon$ transcripts, LTC4S and EAR3 in the normal mucosal tissues and polypoid lesions. Their mRNAs were all increased in $\mathrm{NP}$ compared to those in normal mucosa, and reduced after 2 -APB administration (respectively, $\mathrm{p}<0.0001$, normal vs. NP, $\mathrm{p}<0.0001,30 \mu \mathrm{M}$ vs. NP, $\mathrm{p}<0.0001,50 \mu \mathrm{M}$ vs. NP; $\mathrm{p}<0.0001$, normal vs. NP, $\mathrm{p}<0.001,30 \mu \mathrm{M}$ vs. NP, $\mathrm{p}<0.0001,50 \mu \mathrm{M}$ vs. NP; $<<0.0001$, normal vs. NP, $\mathrm{p}<$ $0.0001,30 \mu \mathrm{M}$ vs. NP, $\mathrm{p}<0.0001,50 \mu \mathrm{M}$ vs. NP; $<<0.0001$, normal vs. NP, $\mathrm{p}<0.0001,30 \mu \mathrm{M}$ vs. NP, $\mathrm{p}<0.0001,50$ $\mu \mathrm{M}$ vs. NP; $\mathrm{p}<0.0001$, normal vs. NP, $\mathrm{p}<0.01,30 \mu \mathrm{M}$ vs. $\mathrm{NP}, \mathrm{p}<0.0001,50 \mu \mathrm{M}$ vs. NP; $\mathrm{p}<0.0001$, normal vs. NP, $\mathrm{p}<0.01,30 \mu \mathrm{M}$ vs. NP, $\mathrm{p}<0.0001,50 \mu \mathrm{M}$ vs. NP; fig. 5). These findings clearly demonstrated that 2-APB treatment effectively ameliorated the mediators in polypoid lesions, and might produce good efficacy in the control of NP formation.

Different Effects on NP after Different Concentrations of 2-APB Treatment

Finally, we investigated whether the effect of 2-APB was dependent on the concentrations of administration. When the cultured NP were administered with 2-APB at a concentration of 30 or $50 \mu \mathrm{M}$, Orail protein and mRNA were reduced in $50-\mu \mathrm{M}$-treated NP in comparison with those treated in $30 \mu \mathrm{M}(\mathrm{p}<0.0001$ and $\mathrm{p}<0.0001$, respectively, 50 vs. $30 \mu \mathrm{M}$; fig. $3 \mathrm{a}, \mathrm{b})$. In addition, the $\mathrm{Ca}^{2+} \mathrm{MFI}$ was also more reduced in the $50-\mu \mathrm{M}$-treated group $(\mathrm{p}<$ $0.0001,50$ vs. $30 \mu \mathrm{M}$; fig. 3c). Similarly, there were statistical differences between these two groups in concentrations of IL-4, IL-5, IL-13, DP-sIgE, LTC4 and ECP (respectively, $\mathrm{p}<0.0001,50$ vs. $30 \mu \mathrm{M} ; \mathrm{p}<0.0001,50$ vs. 30 $\mu \mathrm{M} ; \mathrm{p}<0.0001,50$ vs. $30 \mu \mathrm{M} ; \mathrm{p}<0.0001,50$ vs. $30 \mu \mathrm{M} ; \mathrm{p}<$ $0.0001,50$ vs. $30 \mu \mathrm{M} ; \mathrm{p}<0.0001,50$ vs. $30 \mu \mathrm{M}$; fig. 4 ) and their corresponding mRNAs (respectively, $\mathrm{p}<0.0001$, 50 vs. $30 \mu \mathrm{M} ; \mathrm{p}<0.0001,50$ vs. $30 \mu \mathrm{M} ; \mathrm{p}<0.0001,50$ vs.
$30 \mu \mathrm{M} ; \mathrm{p}<0.001,50$ vs. $30 \mu \mathrm{M} ; \mathrm{p}<0.001,50$ vs. $30 \mu \mathrm{M}$; $\mathrm{p}<0.001,50$ vs. $30 \mu \mathrm{M}$; fig. 5). This revealed that the effect of 2-APB treatment on NP might rely on the concentrations of the administration.

\section{Discussion}

$\mathrm{NP}$ are polypoidal masses arising from the mucosa of the nose and paranasal sinuses [1]. Applied medications like glucocorticoids offer only a symptomatic effect [3], and do not liquidate the cause of this disease. It is assumed that NP develop as a result of concurrent events leading to the damage (especially edema by eosinophilic infiltration) of nasal mucosa [13]. The edema of nasal mucosa is a result of postinflammatory disorders in the functions of $\mathrm{Na}^{+}$and $\mathrm{Cl}^{-}$ion canals [14]. NP are chiefly characterized by eosinophilic inflammation, while other types of ISC, including mast cells, T cells and B cells, also play an important role in the pathologic process of polypoid tissues [1]. SOCE is the principal pathway of $\mathrm{Ca}^{2+}$ influx in mammalian ISC. Stimulation of these cells initiates depletion of $\mathrm{Ca}^{2+}$ from endoplasmic reticulum stores, and triggers sustained $\mathrm{Ca}^{2+}$ entry through CRAC channels, which contributes to their activation and proliferation [5]. Orail protein forms the pore subunit of the CRAC channels. The intervention of this protein may prevent ISC from synthesizing and secreting inflammatory mediators, and then block the NP formation and development. Thus, targeting the CRAC channels may provide a novel strategy for treating NP $[15,16]$.

In this study, we did not differentiate the types of ISC which were positively immunostained for Orail, since there were close relationships among them, and they were all significant in the pathogenesis of NP. According to the immunohistochemical analysis, Orail ${ }^{+}$staining cells were elevated in NP (fig. 1b) in comparison to those in normal mucosa (fig. 1a), and the number of Orai1 ${ }^{+}$inflammatory cells were increased in the former with a semiquantitative method (fig. 1c). This result demonstrated that NP exhibited a high degree of tissue inflammatory cell infiltration and an enhancement of their activation because of the extensive expression of Orail. As a result, Orai $1^{+}$inflammatory cells released proinflammatory cytokines which played important roles in the persistence of mucosal inflammation associated with NP [11]. All in all, Orail expression was upregulated in NP in comparison with that in normal mucosa, whether in protein or in mRNA level (fig. 2a, b). Therefore, the excessive expression of Orail and the activation of CRAC channels 
contributed to a sustained $\mathrm{Ca}^{2+}$ influx, which resulted in the sharp elevation of intracellular $\mathrm{Ca}^{2+}$ in this research (fig. 2c).

2-APB is a dependable blocker of SOCE through inhibition of Orail protein and CRAC channel activity [10], yet the mechanism has not been fully elucidated. Besides blocking CRAC channels, 2-APB also affects other targets, such as transient receptor potential channels [17]. However, many studies have indicated that this drug is a reliable blocker of CRAC channels [10]. Although YM58483 (BTP2) and the antibiotic Geneticin ${ }^{\circledR}$ (G418) have also been reported to interfere with the function of CRAC channels [18], BTP2 may induce degradation of the channels and slow down the recovery of the immune response after treatment [19], and G418 inhibits protein synthesis in mammalian cells and induces cell death of native cells [18]. It has not been reported that 2-APB has specific side effects, as mentioned above. Therefore, 2-APB has emerged as the most valuable pharmacological tool with which to investigate CRAC channel function [18]. In this present study we also chose 2 -APB as the intervention agent. Orail production and $\mathrm{Ca}^{2+}$ MFI were elevated in the cultured NP compared to those in the normal mucosa, and were lessened after the in vitro 2 -APB application (fig. 3) in the present study. This result indicated that 2 -APB could intervene in protein expression and the channels formed by it in the tissue cells of NP.

NP tissues are characterized by intense eosinophilic infiltration and a Th2-based cytokine profile including IL-4, IL-5 and IL-13 [20]. Although mast cells have been shown to produce these mediators, they are major cytokines stored and released by Th2 cells $[21,22]$. These Th2 cytokines were found to be increased in NP compared with those in normal mucosa (fig. $4 \mathrm{a}-\mathrm{c}, 5 \mathrm{a}-\mathrm{c}$ ). However, 2 -APB treatment $(30$ or $50 \mu \mathrm{M})$ produced inhibitory effects on them. The productions in the cultured NP were reduced (fig. $4 a-c, 5 a-c)$. This might be connected with the intervention of Orail protein and CRAC channels by this drug in Th2 cells, which in turn controlled the activation of these lymphocytes and the corresponding cytokine release and synthesis by them.

Regarding IgE-mediated NP generation, there have been a few studies demonstrating increased production of IgE within NP tissues $[23,24]$. Other studies have further shown that DP-sIgE can stimulate eosinophil recruitment and degranulation, resulting in the release of cytotoxic proteins such as ECP and eosinophil peroxidase in in vitro conditions and in NP $[25,26]$. DP-sIgE and germline $\mathrm{C} \varepsilon$ transcript were upregulated in NP versus those in normal mucosa (fig. $4 \mathrm{~d}, 5 \mathrm{~d}$ ) in the present study.
Yet, according to the data, 2-APB limited their production (fig. $4 \mathrm{~d}, 5 \mathrm{~d}$ ). It is well known that DP-sIgE is secreted from plasma cells after B cell differentiation in NP [27]. 2-APB might fulfil the prohibitive function via controlling Orail protein expression and CRAC channel activities in these cells' plasma membrane. The downregulation of the specific immunoglobulin also led to the decrease of ECP production due to its function on eosinophils in this investigation [27].

Mast cells play a crucial role in the development of polypoid tissues. Many studies indicate mast cell abundance and distribution in NP [28], and show that chemical mediators such as LTC4 degranulation from the cells can produce profound tissue edema [29, 30]. LTC4 and LTC4S mRNA were all enhanced in the polyp cultures in comparison with those in the normal mucosa cultures (fig. 4e, 5e). Nevertheless, they were decreased after 2 -APB administration (fig. 4e, 5e). This mechanism might have occurred because the intervention of Orail protein and CRAC channels in mast cells reduced their degranulation and synthesis of LTC4.

ECP is one of the primary cationic proteins from eosinophils, and is toxic to respiratory epithelium [31]. It has been reported that IL- 5 is one of the numerous potent activators and regulators of eosinophil function [32]. Eosinophil infiltration and activation may cause tissue damage through the release of ECP, and the elevated ECP level also characterizes the eosinophilic inflammation in polyp tissues [33]. This investigation demonstrated a higher level of ECP in NP compared to that in normal mucosa (fig. 4f, 5f), which suggested the eosinophil effector function in the formation of polyp tissues. However, the data showed the amelioration of ECP in the protein and its EAR3 mRNA in the culture after 2-APB treatment (fig. 4f, 5f). Additionally, no confirmed reports have so far described the definite expression of Orail protein and CRAC channels in eosinophils. Therefore, it was assumed that 2-APB could not influence the activation and degranulation of eosinophils directly. This drug might diminish IL-5 secreted from T cells and DP-sIgE released from plasma cells through its impediment of Orail protein and CRAC channels in these cells, which then decreased the ECP concentration in NP indirectly.

Finally, As shown in figures $3-5,50 \mu \mathrm{M} 2$-APB treatment reduced the production of Orail, IL-4, IL-5, IL-13, DP-sIgE, LTC4 and ECP, their corresponding mRNAs and the content of $\mathrm{Ca}^{2+}$ MFI more than the $30 \mu \mathrm{M}$ treatment did. This outcome indicated that the impact of 2-APB on NP might be dependent on the concentrations of the administration used in this current experiment. 
In summary, Orai1 was expressed in submucosal inflammatory cells in NP, and the numbers of Orai1 ${ }^{+}$inflammatory cells were increased in polypoid tissues. The expressions of Orai 1 and $\mathrm{Ca}^{2+}$ MFI were all upregulated, and then downregulated after 2-APB administration in NP. IL-4, IL-5, IL-13, DP-sIgE, LTC4 and ECP and their corresponding mRNAs were all increased in the cultures of NP, and decreased after in vitro treatment of 2-APB. However, the mechanisms underlying the inhibitory function of 2-APB in the development of NP need to be further identified. It should be emphasized that Orail and CRAC channels might play an important role in NP formation and development, and the intervention of this protein may inhibit this disease according to the results presented here. The drug design strategies for the inter- ference of Orail protein and CRAC channels in ISC may offer novel and effective therapeutic and/or prophylactic means to treat patients with CRSwNP.

\section{Acknowledgments}

This work was supported by the Science Research Program of Shanghai Municipal Health Bureau (No. 20114145) and the National Natural Science Foundation of China (No. 81371076).

\section{Disclosure Statement}

The authors declare that they have no conflicts of interest.

\section{References}

1 Stoop AE, van der Heijden HA, Biewenga J, van der Baan S: Eosinophils in nasal polyps and nasal mucosa: an immunohistochemicalstudy. J Allergy Clin Immunol 1993;91:616622.

2 Bachert C: Evidence-based management of nasal polyposis by intranasal corticosteroids: from the cause to the clinic. Int Arch Allergy Immunol 2011;155:309-321.

3 Fokkens WJ, Lund VJ, Mullol J, Bachert C, Alobid I, Baroody F, Cohen N, Cervin A, Douglas R, Gevaert P, Georgalas C, Goossens H, Harvey R, Hellings P, Hopkins C, Jones N, Joos G, Kalogjera L, Kern B, Kowalski M, Price D, Riechelmann H, Schlosser R, Senior B, Thomas M, Toskala E, Voegels R, Wang de Y, Wormald PJ: European Position Paper on Rhinosinusitis and Nasal Polyps 2012. Rhinology 2012;50(suppl 23):1-298.

4 Berridge MJ, Bootman MD, Roderick HL: Calcium signaling: dynamics, homeostasis and remodeling. Nat Rev Mol Cell Biol 2003; 4:517-529.

5 Vig M, Peinelt C, Beck A, Koomoa DL, Rabah D, Koblan-Huberson M, Kraft S, Turner H, Fleig A, Penner R, Kinet JP: CRACM1 is a plasma membrane protein essential for storeoperated $\mathrm{Ca}^{2+}$ entry. Science 2006;312:12201223.

6 Feske S, Gwack Y, Prakriya M, Srikanth S, Puppel SH, Tanasa B, Hogan PG, Lewis RS, Daly M, Rao A: A mutation in Orail causes immune deficiency by abrogating CRAC channel function. Nature 2006;441:179-185.

7 Gwack Y, Feske S, Srikanth S, Hogan PG, Rao A: Signaling to transcription: store-operated $\mathrm{Ca}^{2+}$ entry and NFAT activation in lymphocytes. Cell Calcium 2007;42:145-156.

8 Rao A, Luo C, Hogan PG: Transcription factors of the NFAT family: regulation and function. Annu Rev Immunol 1997;15:707-747.
9 Bachert C, van Bruaene N, Toskala E, Zhang $N$, Olze $H$, Scadding $G$, van Drunen $C M$, Mullol J, Cardell L, Gevaert P, van Zele T, Claeys S, Halldén C, Kostamo K, Foerster U, Kowalski M, Bieniek K, Olszewska-Ziaber A, Nizankowska-Mogilnicka E, Szczeklik A, Swierczynska M, Arcimowicz M, Lund V, Fokkens W, Zuberbier T, Akdis C, Canonica G, van Cauwenberge P, Burney P, Bousquet J: Important research questions in allergy and related diseases: 3 -chronic rhinosinusitis and nasal polyposis - a GALEN study. Allergy 2009;64:520-533.

10 Peinelt C, Lis A, Beck A, Fleig A, Penner R: 2-Aminoethoxydiphenyl borate directly facilitates and indirectly inhibits STIM1-dependent gating of CRAC channels. J Physiol 2008; 586:3061-3073.

11 Park SK, Lee WJ, Yang YI: Organ culture at the air-liquid interface maintains structural and functional integrities of inflammatory and fibrovascular cells of nasal polyps. Am J Rhinol 2007;21:402-407.

12 Lin L, Zhao X, Yan W, Guo Y, Liang S: Amelioration of Muc5b mucin hypersecretion is enhanced by IL-33 after 2-APB administration in a murine model of allergic rhinitis. Biotech Histochem 2014;89:273-286.

13 Arcimowicz M, Balcerzak J, Samoliński BK: Nasal polyps is not a homogenous pathology. Pol Merkur Lek 2005;19:276-279.

14 Bernstein JM, Yankaskas JR: Increased ion transport in cultured nasal epithelial cells. Arch Otolaryngol Head Neck Surg 1994;120: 993-996.

15 Di Capite J, Nelson C, Bates G, Parekh AB: Targeting $\mathrm{Ca}^{2+}$ release-activated $\mathrm{Ca}^{2+}$ channel channels and leukotriene receptors provides a novel combination strategy for treating nasal polyposis. J Allergy Clin Immunol 2009;124: 1014-1021.e1-3.
16 Di Capite J, Shirley A, Nelson C, Bates G, Parekh AB: Intercellular $\mathrm{Ca}^{2+}$ wave propagation involving positive feedback between CRAC channels and cysteinyl leukotrienes. FASEB J 2009;23:894-905.

17 Harteneck C, Gollasch M: Pharmacological modulation of diacylglycerol-sensitive TRPC 3/6/7 channels. Curr Pharm Biotechnol 2011;12:35-41.

18 Bogeski I, Al-Ansary D, Qu B, Niemeyer BA, Hoth M, Peinelt C: Pharmacology of ORAI channels as a tool to understand their physiological functions. Expert Rev Clin Pharmacol 2010;3:291-303.

19 Steinckwich N, Frippiat JP, Stasia MJ, Erard M, Boxio R, Tankosic C, Doignon I, Nüsse O: Potent inhibition of store-operated $\mathrm{Ca}^{2+}$ influx and superoxide production in HL60 cells and polymorphonuclear neutrophils by the pyrazole derivative BTP2. J Leukoc Biol 2007; 81:1054-1064.

20 Bachert C, Wagenmann M, Hauser U, Rudack C: IL-5 synthesis is upregulated in human nasal polyp tissue. J Allergy Clin Immunol 1997;99:837-842.

21 Bradding P, Feather IH, Wilson S, Bardin PG, Heusser CH, Holgate ST, Howarth PH: Immunolocalization of cytokines in the nasal mucosa of normal and perennial rhinitic subjects: the mast cell as a source of IL-4, IL-5, and IL-6 in human allergic mucosal inflammation. J Immunol 1993;151:3853-3865.

22 Bradding P: The role of the mast cell in asthma: a reassessment. Curr Opin Allergy Clin Immunol 1993;3:45e50.

23 Matsuwaki Y, Uno K, Okushi T, Otori N, Moriyama H: Total and antigen- (fungi, mites and staphylococcal enterotoxins) specific IgEs in nasal polyps is related to local eosinophilic inflammation. Int Arch Allergy Immunol 2013;161(suppl 2):147-153. 
24 Kang JW, Nahm DH, Suh KS, Kim HY, Park HS: Local production of specific IgE antibody to house dust mite in nasal polyp tissue. J Asthma Allergy Clin Immunol 1998;18:426433.

25 Tomassini M, Tsicopoulos A, Tai PC, Gruart V, Tonnel AB, Prin L, Capron A, Capron M: Release of granule proteins by eosinophils from allergic and nonallergic patients with eosinophilia on immunoglobulin-dependent activation. J Allergy Clin Immunol 1991;88: 365-375.

26 Suh KS, Park HS, Nahm DH, Kim YK, Lee YM, Park K: Role of IgG, IgA, and IgE antibodies in nasal polyp tissue: their relationships with eosinophilic infiltration and degranulation. J Korean Med Sci 2002;17:375380.
27 Gevaert P, Nouri-Aria KT, Wu H, Harper CE, Takhar P, Fear DJ, Acke F, De Ruyck N, Banfield G, Kariyawasam HH, Bachert C, Durham SR, Gould HJ: Local receptor revision and class switching to IgE in chronic rhinosinusitis with nasal polyps. Allergy 2013;68:5563.

28 Pawankar R: Mast cells in allergic airway disease and chronic rhinosinusitis. Chem Immunol Allergy 2005;87:111-129.

29 Abraham SN, St John AL: Mast cell-orchestrated immunity to pathogens. Nat Rev Immunol 2010;10:440-452.
30 Adamusiak AM, Stasikowska-Kanicka O, Lewandowska-Polak A, Danilewicz M, Wagrowska-Danilewicz M, Jankowski A, Kowalski ML, Pawliczak R: Expression of arachidonate metabolism enzymes and receptors in nasal polyps of aspirin-hypersensitive asthmatics. Int Arch Allergy Immunol 2012;157: 354-362.

31 Gleich GJ: Mechanisms of eosinophil-associated inflammation. J Allergy Clin Immunol 2000; 105:651-663.

32 Arcimowicz M, Balcerzak J, Samoliński BK: Nasal polyps is not a homogenous pathology. Pol Merkur Lek 2005;19:276-279.

33 Perez-Novo CA, Claeys C, van Cauwenberge P, Bachert C: Expression of eicosanoid receptors subtypes and eosinophilic inflammation: implication on chronic rhinosinusitis. Respir Res 2006;7:75. 